\title{
A CONSTRUÇÃO DA PERSONAGEM NA LITERATURA DE SACOLINHA
}

\section{Luciana Sacramento Moreno Gonçalves*}

RESUMO: No final dos anos 90 do século XX, surge na cena literária brasileira uma literatura, designada por alguns de periférica, por outros de marginal ou até mesmo divergente. Essa escrita brasileira contemporânea tem criado espaços importantes no mercado editorial, interessado à crítica especializada e ampliado o número de leitores implicados a ela. Por isso, compreendemos como fundamental estudá-la, reconhecendo a necessidade de alçar tais produções artísticas a um número cada vez mais amplo de leitores pelo seu potencial singular na formação destes, sobretudo, aqueles que se situam na faixa etária da juventude e em contextos periféricos. Assim, esta comunicação apresenta uma análise em torno do processo de elaboração das personagens na produção de um dos principais expoentes desta cena: o Escritor Sacolinha. Em seus livros de contos, observamos a presença de personagens atuais, homens e mulheres que circulam nas localidades pobres brasileira. Todavia, para este autor o destaque está nos aspectos subjetivos e comportamentais, em detrimento de caracterizações físicas e materiais, evidenciando a busca em humaniza-los e em trata das complexidades destes. A metodologia utilizada é a pesquisa bibliográfica, com abordagem qualitativa e interpretativa. Para tanto, referenda-se em Resende (2008), Schollhammer (2011), Dalcastagné (2012) no que se refere a literatura brasileira contemporânea. Apoia-se em Nascimento (2009), Hollanda (2013, 2015), Reys (2013) para discutir a literatura periférica. E em Beth Braith (1985) e Rosenfeld (1968) e Cuti (2010), para tecer a análise dos personagens. Neste movimento, percebe-se que Sacolinha opta ao construir as personagens protagonistas de seus contos por minimizar a descrição física e valorizar o perfil psicológico no intuito de levar o leitor a enxergar tais personagens tão próximos e que circulam no cotidiano das sociedades contemporâneas, por um prisma muitas vezes ignorados pelas coletividades e sobretudo pelo poder público.

PALAVRAS-CHAVE: Literatura Brasileira Contemporânea; Periferia; Escritor Sacolinha; Personagem.

\footnotetext{
* Professora Adjunta da Universidade do Estado da Bahia (Uneb), Campus XIII. Docente do Programa de Pósgraduação em Estudo de Linguagens da Uneb. Doutora em Letras pela Pontifícia Universidade Católica do Rio Grande do Sul (Puc-RS).
} 


\section{Notas introdutórias}

Este artigo trata dos personagens protagonistas presentes no livro Brechó, Meia-noite e Fantasia (2015), de Sacolinha e das estratégias, realizadas pelo referido autor, para a construção destes. Observa-se que os personagens são fundamentais nas narrativas deste escritor. Estes são algumas vezes os párias sociais ou os injustamente marginalizados ou homens e mulheres periféricos que transitam em nós e por nós (porque muitos nós conhecemos e muitos somos nós mesmos). O que particulariza "esse desfile de tipos humanos", no dizer de Carrascoza (2016) é, primeiro: a humanização deles, pois por mais vis que possam ser, sempre encontramos uma centelha daquilo que Candido assim explicou como o:

(...) processo que confirma nos homens aqueles traços que reputamos essenciais, o exercício da reflexão, a aquisição do saber, a boa disposição para com o próximo, os afinamentos das emoções, a capacidade de penetrar nos problemas da vida, o senso da beleza, a percepção da complexidade do mundo e dos seres, o cultivo do humor. (CANDIDO, 1994).

Assim, além de encontrarmos esse emaranhado de traços primordiais da humanização dos humanos na literatura de Sacolinha, deparamo-nos com mecanismos de elaboração de personagens que se confirmam pela égide do inusitado: os pedreiros são poetas; os escritores vendem livros na rua com o intuito de comer um yakissoba para aplacar a fome; a prostituta por vocação é leitora de Proust; o pai que deseja a filha se pune e se consome, mas não consolida o prazer carnal; os moradores em situação de rua se aninham e vivem o amor entre iguais.

Sacolinha é o pseudônimo de Ademiro Alves de Souza que nasceu em São Paulo, foi criado na periferia de Itaquera e migrou para a cidade de Suzano, lugar onde vive atualmente com sua família, ainda entre a infância e a adolescência. Formado em Letras, é professor da Educação Básica Estadual, já atuou na Secretaria de Cultura da cidade onde mora e realiza diversos projetos artísticos e culturais, em prol da leitura, literatura, formação de leitores e escritores. 
Para Sacolinha, o conto é fragmento da própria vida e se aproxima do romance, por também ser uma narrativa em prosa. No entanto, isso ocorre sem demandar a longa extensão daquele em relação ao número de conflitos, de personagens e cenários. No conto, relata-se, portanto, apenas uma parte da existência humana. Esta não é menos complexa. Pelo contrário, ela traz em si um 'quê' de surpresa e revelação. Para o autor, o conto é um gênero que conforta de certa maneira o leitor, por sua breve extensão e por resolver a situação com maior celeridade. A ideia é captar essa fração de vida e contá-la aos seus leitores de uma maneira que estes se envolvam com o desenrolar da trama e encontrem uma inspiração pela via do inesperado.

\section{As margens periféricas na literatura brasileira contemporânea}

A produção literária contemporânea é destacada por Rezende (2008) como fértil. Esta pesquisadora inclui nessa caracterização a coexistência de uma multiplicidade de vozes como marca singular deste momento. Já Schollhammer (2011) elenca como aspecto desta cena a urgência em se relacionar com a realidade histórica e deflagra uma literatura que ao tratar de questões sociais não exclui a dimensão pessoal e íntima. Para ele, a ficção contemporânea deve ser compreendida pelo entrelaçamento entre o engajamento realista e a intimidade autobiográfica (SCHOLLHAMMER, 2011).

Entretanto, Dalcastgné (2012) ressalta que apesar deste cenário em que a diversidade se apresenta como aspecto fundamental, há uma homogeneidade no campo literário brasileiro. Este confirma a exclusão e consequente tentativa de silenciamento das produções das populações negras, pobres, de mulheres e LGBTQ. Todavia, no final dos anos 90 do século XX, impulsionados pela popularização das tecnologias de informação e comunicação e também pela ampliação aos acessos à educação e aos bens de consumo, emerge dentro das periferias urbanas brasileiras, uma literatura produzida por sujeitos que conhecem tais espaços através de suas experiências cotidianas, porque nasceram e/ou vivem nestas localidades geográficas. 
Segundo Reyes, a literatura produzida nas periferias apresenta “(...) novos desafios no contexto da história da literatura brasileira: pelo conteúdo, pela forma, pela linguagem e, sobretudo, pelo lugar de enunciação” (REYES, 2013, p. 15). Para este autor, esta literatura, desenvolvida em espaços historicamente alijados do acesso ao livro, a leitura e a literatura, revela-se como combativa, rebelde e criativa.

Holanda sinaliza que “(...) a nova cultura da periferia se impõe como um dos movimentos culturais de ponta no país, com feição própria, uma indisfarçável dicção proativa e, claro, projeto de transformação social”. (HOLLANDA, 2009, p. 4,). O que confirma sua inserção em questões problemáticas da contemporaneidade, sem restringir-se a uma produção meramente documental.

Nascimento (2009) traça vasto panorama de caracterizações da Literatura periférica, aludindo aos temas mais recorrentes como "violência, carência de bens e equipamentos culturais, precariedade da infraestrutura urbana, relações de trabalho - predominantemente associados ao espaço social da periferia" (NASCIMENTO, 2009, p. 47-48). Observa também uma variedade de adjetivos para designar esta literatura, inicialmente chamada de marginal e/ ou periférica, para posteriormente abarcar termos como negra ou divergente. Todavia, o que agrega todas essas designações é:

Uma experiência comum da exclusão, um dano, uma queixa (no sentido jurídico da palavra), uma ofensa, uma injuria. Injuriado somos. Talvez seja a condição atual da reivindicação da identidade (s); o status litigante, a queixa constitutiva, a ofensa que nos faz". (PENA, 2016, p. 13)

Observa-se que todas essas adjetivações possuem um legado de pejo e negatividade. Entretanto, nestes casos, são usadas intencionalmente para valorizar tais termos e subverter a concepção sobre os mesmos, positivando-os. Apesar disso, não há homogeneidade nos nomes nem nas experiências. Há divergências que ampliam a própria cena e confirmam sua complexidade. 
Neste contexto, pensar aspectos específicos do texto literário, como a construção de personagem é quesito importante para problematizar como essas estratégias de elaboração do texto narrativo são percorridos por um escritor. Isso se potencializa quando se trata da cena literária negra periférica, pois ainda há espaços para uma crítica desta cena que não se restrinja a sua importância sociológica, mas que confirme que sua produção não é meramente testemunhal.

Todavia, vale ainda confirmar que personagem não é pessoa, pois esta é um ser vivo e aquele é um ser ficcional. O personagem é um ser linguístico, que não existe, portanto, fora da linguagem. Assim, conforme afirma Beth Brait (1985, p. 9) "Se quisermos saber alguma coisa a respeito de personagens, teremos de encarar frente a frente a construção do texto, a maneira que o autor encontrou para dar forma às suas criaturas, e aí pinçar a independência, a autonomia e a "vida" desses seres de ficção".

O problema é que ficção e realidade possuem relação íntima e difícil de separar. São os recursos de linguagem que fazem parte do repertório do autor, o responsável pela forma como este artisticamente irá inventar os personagens que transitam em seus textos. Para tal, geralmente, os escritores investem na escolha de um nome e, algumas vezes, até sobrenome para individualizar estes seres. Recorrem a apresentações psicológicas dos mesmos. E, a depender da intenção do autor e ou da extensão da narrativa, indicam sua história familiar, sua função social, seus comportamentos e sentimentos. Descrevem também aspectos físicos dos mesmos de maneira superficial ou detalhada.

Entretanto, quando se pensa na literatura brasileira e na construção de personagens negros e periféricos há de se ter um olhar mais atento, porque a construção dos personagens tem se erigido pelo esteio da estereotipia. Cuti (2010, p. 16) afirma que a escravização tornou homens e mulheres africanos e afro-brasileiros associados a objetos. Desta forma, "A literatura, como reflexo e reforço das relações tanto sociais quanto de poder, atuará no mesmo sentido ao caracterizar as personagens negras, negando-lhes complexidades e, portanto, humanidade" (CUTI, 2010, p. 16). 
Ao ler a literatura de Sacolinha enxerga-se uma perspectiva que vai na contramão desta anteriormente citada, porque tal escritor humaniza seus personagens e os complexiza ao focar em aspectos historicamente negligenciados e ao optar por descrevê-los muito mais comportamentalmente do que fisicamente. Sequer aborda em seus textos os "os males da escravidão como estatuto legal" (CUTI, 2010, p. 27). Apresenta fortemente temais raciais e periféricos, mas não se limita ao discurso da escassez material, do crime, da violência, do tráfico, do racismo, da exploração. Aborda desde questões de escolha e filosofia de vida, passando pelos desafios da escrita literária, até temas como amor, tragédia e superação.

\section{Personagens atuais da cena periférica? presentes!}

Na orelha do livro "Brechó, Meia-noite e Fantasia", feita pelo escritor e professor universitário João Azanello Carrascoza, este afirma identificar os tipos humanos que passeiam nos contos, indicando-os como contemporâneos e orienta o leitor que encontrará aqueles que são esquecidos ou marginalizados ou invisibilizados socialmente, ou melhor, "gente singela, em todo sua complexidade" (CARRASCOZOA, 2016, p. 6). Estes personagens são tipos aparentemente conhecidos, sobretudo, na trama do popular, mas vistos por um viés “inédito”, inesperado, incomum. Na superfície, são simples, mas quando o autor verticaliza e os apresenta com amplitude, o leitor tem acesso a uma visão diferenciada do mesmo.

Nos contos de Sacolinha, presentes no livro "Brechó, Meia-noite e Fantasia”, observamos a voz do próprio autor. A provável razão disso é que é mais confortável para os escritores falarem da realidade em que vivem, a partir das questões geográficas, raciais, etárias, de gênero e sexualidade a que se filiam. Apesar disso, demarcamos que no caso do Escritor Sacolinha apesar de deflagrarmos a superior presença dos grupos masculinos, periféricos, negros, jovens e heterossexuais, observamos também o aparecimento do desejo, que provavelmente faz parte de seu projeto estético, de se arriscar a falar outras vozes que não são necessariamente as que interpelam o corpo e a história do próprio escritor. 
Neste contexto, para tratar da questão dos personagens, pensar os focos narrativos é relevante, pois ora personagem e narrador se confundem, ora temos um narrador que conhece a fundo todos os meandros da trama, mas não vivencia as ações ali narradas. Para Beth Brait: “Qualquer tentativa de sintetizar as maneiras possíveis de caracterização de personagens esbarra necessariamente na questão do narrador, esta instância narrativa que vai conduzindo o leitor por um mundo que parece estar se criando à sua frente" (BRAIT, 1985 , p. 53).

Em oito dos contos do livro, o narrador é em terceira pessoa. É aquele que observa a cena de cima, conhecendo detalhes do enredo, que por muitas vezes os próprios personagens ignoram. Há três contos cujos narradores são personagem, portanto o foco narrativo se encontra em primeira pessoa. Destacamos o conto "Valsa dos 15 anos", porque no que se refere ao foco narrativo opta por uma ruptura no modelo tradicional de conto, pois está em primeira pessoa, entretanto a história é contada por duas perspectivas (a da filha e a do pai) e no texto esta diferenciação é explicitada através de marca gráfica: o uso do itálico.

Sobre a nomeação dos personagens para confirmar sua individuação, Sacolinha opta por este uso. Vê-se que somente dois protagonistas não possuem nome declarado, pois são a voz do próprio autor que se designa como “o escritor”. São os textos que se encontram em primeira pessoa do singular. Incluímos estes dois no rol de personagens homens, negros, periféricos, de idade adulta, porque o Escritor Sacolinha apresenta essas características. Neste conjunto, provavelmente aparecem mais dez de seus protagonistas (Batata do Rolo, Papai, Vitor Régis, Digão, Neto, João Marina, Erasmo, Brechó, Meianoite e Fantasia).

Destaco que apenas em quatro contos, os protagonistas não são apresentados a partir de seu nome próprio (Batata do Rolo, Papai, Digão, Neto, Brechó, Meia noite e Fantasia). Infere-se que o personagem Batata do Rolo é designado através de um apelido associado a sua função social (rolo), por viver em situação de exclusão, ser um acumulador e vendedor de sucatas, não possuir um emprego formal e trabalhar com o lixo. Tal situação 
também ocorre com Brechó, Meia-noite e Fantasia, cujos personagens desconhecemos os nomes oficiais, pois na esfera pública são tratados socialmente como inferiores (são mendigos). No caso de Digão e Neto, usar os apelidos refere-se, sobretudo, as maneiras carinhosas pelas quais eles são conhecidos e reconhecidos no bairro desde a infância, o que evoca mais situações afetivas da memória, do que marcas de exclusão. Por último, no conto Valsa dos 15 anos, refere-se apenas a Papai, para marcar o conflito do genitor desejar a própria filha ou talvez para preservar o nome deste homem, já que se percebe certa solidariedade com o conflito interno experienciado por este pai que deseja a filha.

Assim, na maior parte dos contos, estes seres, homens e mulheres, periféricos e negros, são nomeados de forma declarada, até porque Lélia Gonzalez (2018) nos sinaliza: "negro tem que ter nome e sobrenome, senão os brancos arranjam um apelido... ao gosto deles". Parece que essa estratégia faz parte do projeto estético e político do Escritor Sacolinha. Porque ao nomear os personagens com seus nomes oficiais, o escritor se afasta da banalização dos mesmos e obriga seus leitores a os reconhecerem não só por uma relação com aspectos raciais ou sociais, mas pela multiplicidade de possibilidades que cada um desses seres ficcionais abarca.

Quanto a questão de gênero, confirmamos a supremacia da presença de homens (13) e a tentativa de representar a voz de mulheres (em 5 protagonistas), mas também a heteronormatividade como marca recorrente. Ressalta-se que no último conto, aparecem três homens, que experimentam outras orientações sexuais, pautadas no homoafeto. Sobre as mulheres que aparecem como protagonista, temos a púbere Rosenda que tem voz própria apesar de só ter ciência de parte da situação narrada (sabe da mudança de comportamento do pai, mas desconhece o desejo que este nutre por ela). As três jovens de classes sociais distintas e por isso diferentes acessos ao conhecimento e a garantia de direitos também protagonizam um dilema especificamente feminino em nossa sociedade, a questão do aborto. Por último, Naolana, “a rainha de si”, é uma voz feminina marcada pela resiliência e pela ampliação da definição de rainha. 
Nos contos, não é a questão de gênero que determina força, resiliência e coragem. Há homens com autoestima elevada como João Marina, do Muro de Arrimo e homens frágeis, medrosos e inseguros, como Erasmo do Medo do medo. Há mulheres resilientes, que enfrentam os dramas pessoais, negociam com os homens e se posicionam no mesmo patamar discursivo e comportamental deles, como Noalana, Glória Luiza e Lorena e mulheres pouco ativas e que aceitam às condições a que são subjugadas como Maria e Rosenda.

Confirmamos a presença de personagens periféricos em quase a totalidade dos contos. Eles vivem em bairros com poucos equipamentos culturais, cujas condições estruturais são deficitárias. Pertencem às classes trabalhadoras e acessam instituições públicas de saúde e ensino (quando tem a oportunidade de acessá-la regularmente). Experimentam ao mesmo tempo, a violência diária, atrelada às situações de sociabilidades que evocam camaradagem, parceria e esperança.

Ponto de grande relevância na construção dos personagens do escritor Sacolinha centra-se na pouca presença das descrições físicas e materiais dos mesmos. As literaturas associadas a questões sociais são geralmente inferiorizadas por questões da linguagem, o não uso da norma culta, por exemplo, como também são dissociadas do literário e relacionadas a uma mera escrita documental da realidade justamente por evidenciar um excesso de descrições objetivas de cenário e personagens, muitas vezes, apresentando o que está na superfície (ou no visível), sem se dedicar ao que está no interno, comportamental (o sensível).

Nos contos analisados, os aspectos físicos dos personagens são tratados de forma são explicitados objetivamente, todavia não se dedica uma adjetivação detalhada a tais aspectos. Em contrapartida, o psicológico é amplamente evidenciado. De aspectos físicos, aparecem a questão sexual (se são biologicamente homens ou mulheres). Os demais índices aparecem como pistas do texto, como sua faixa etária, o fato de viverem ou terem nascido ou transitarem em espaços geograficamente periféricos e alguns índices sobre cor/raça dos mesmos. Em alguns contos (em média, cinco), a descrições físicas sequer aparecem. 
No entanto, comumente mostra-se um histórico de vida do personagem para que o leitor compreenda seu momento atual e, sobretudo, aquele flash que será narrado no conto. Caracteriza o comportamento do personagem, apresentando a complexidade desses aspectos sociais, culturais e psicológicos, indicando que superficialmente, Batata do Rolo, por exemplo, pode ser visto, como um vendedor de sucatas. Todavia, ao o observamos mais atentamente, compreenderemos que ele possui uma importante, apesar de marginalizada, função social: ele acumula o que é descartado socialmente, mas possui valor histórico, afetivo e social.

No conto, a preocupação está mais em apresentar os conflitos dos personagens do que em narrar um acontecimento apenas. A ação central do enredo aparece como reflexo dos comportamentos e práticas culturais, sociais e históricas dos personagens. A ideia é fazer com que o leitor experimente, por exemplo, a angústia e o conflito de escritores que precisam escrever um texto sobre um tema específico, mas apesar de em primeiro plano não terem êxito em seu objetivo inicial, o próprio relato do insucesso já se configura por si só em texto.

As descrições dos sentimentos e posicionamentos dos personagens diante da vida são centrais nas narrativas. Em Batata do Rolo, o escritor utiliza quase $80 \%$ do número de páginas para tal, dedicando-se a relatar a ação (o protagonista é questionado por acumular coisas) somente ao final do conto. Em Valsa dos 15 anos, conhecemos tanto a ingênua, observadora e desamparada Rosenda e sofremos com o ressentimento da filha pelo afastamento do pai, como também, de certa forma, reconhecemos tanto o tormento paterno, seu conflito interno e solitário quanto sua iniciativa de autopunição por desejar a filha, incluindo até mesmo o suicídio como possibilidade para resolução do conflito.

Em muitos dos contos, Sacolinha indica a profissão do protagonista ou sua função social. Temos trabalhadores da construção civil, vendedores de sucatas, escritores, estudantes, ajudante geral, pedreiro. Observam-se nesses perfis profissionais uma multiplicidade de trajetórias dentro do próprio conto. O vendedor de sucata é tratado socialmente como um acumulador, mas comporta-se como um filósofo; o pedreiro é um poeta (escreve 
como observador da vida); a ajudante geral é por algum tempo uma rainha de bateria de escola de samba, mas tratada socialmente com a deferência que se tratam os soberanos e no decorrer do conto forma-se na universidade, tornando-se no desfecho do texto "rainha de sua vida".

No último conto são todos moradores em situação de rua. Dois deles, ex detentos. No passado, cada um teve uma atuação específica e complexa. Um era pintor. Outro era segurança de posto médico que acumulava a função de curandeiro, pois reestabelecia a saúde daqueles que os médicos não conseguiam tratar e por sua fama (e causa de sua derrocada) virou político. O último parece nunca ter trabalhado, vive a imaginação e por receber uma herança e gastá-la toda vai morar na rua.

Quanto a questão da escolarização, a maior parte deles termina a escola básica tardiamente, sobretudo porque, na idade regular migram de suas regiões, viram trabalhadores na infância e/ou adolescência ou ainda estão em processo formativo (como a adolescente Rosenda e as jovens Glória Luiza, Maria e Lorena). João Marina foi trabalhador infantil, mas esta caracterização não é tratada como exploração, e sim como momento preparatório para a formação do protagonista. Este especificamente desempenha uma profissão de baixo prestígio social (pedreiro), mas por ser profissional de excelência (é descrito no conto a partir dos adjetivos competente, respeitado, disputado, dedicado, bom trabalhador, perfeccionista), e é tratado com reverência. Há apenas duas estudantes universitárias (Naolana e Lorena).

Em Jovens anseios, as descrições históricas e comportamentais são fundamentais para o leitor compreender porque cada uma das jovens, apesar de vivenciarem o mesmo dilema (gravidez indesejada x prática do aborto) terão destinos completamente diferentes. Glória Luiza tem foco e metas definidas, anseia cursar medicina. É, ambiciosa, deseja a vida pública e até uma carreira política. Possui certa vantagem econômica e uma rede de amigas, que sinalizam métodos alternativos (chás) tanto para o aborto, quanto para a dispensa da culpa e a sensação de alívio pela prática do aborto. Já Lorena tem alto poder aquisitivo, e a 
partir disso, revela conhecimento do próprio corpo, anseio de correr o mundo. Rica e viajada, vai resolver o problema na Inglaterra. Lá, acessa cuidados médicos e sua vida se normaliza pós- aborto. Já Maria é a mais pobre. Descrita como ingênua, desinformada, opta pelo coito interrompido como método de prevenção. Também possuía sonhos de futuro: desejava ser modelo (o que pode evidenciar além da questão social, uma opção por privilegiar mais o corpo do que o intelecto). É aparentemente romântica e ao saber da gravidez pensa nos efeitos negativos que a notícia pode causar socialmente. Como diarista, acessa uma clínica clandestina para fazer o aborto e acaba morrendo.

Três histórias que se aproximam pela temática, mas seus desfechos diferem pela história pessoal de cada uma delas, como também pelas suas características subjetivas e pelos seus comportamentos diante da situação. O desfile de personagens atuais e periféricos marca os contos presentes no livro analisado. Muitos deles, como já afirmado anteriormente, se aproximam das realidades contemporâneas radicalmente.

\section{Considerações finais}

Confirma-se que nos contos presentes no livro "Brechó, Meia-noite e Fantasia", o escritor Sacolinha dedica-se a apresentar amplamente seus personagens, sobretudo aquele que protagonizará a cena. Todavia, a abordagem psicológica, comportamental sobrepujará a física, material, visual. Há um centramento no personagem e uma tentativa de humanizalos, sobretudo por se tratarem geralmente daqueles ignorados e marginalizados historicamente.

Todos conhecemos (ou já ouvimos falar) de feiras do rolo e seus vendedores, escritores em crise, relações de incesto, homens apaixonados, pessoas com saudade da infância, jovens que engravidam precocemente, pedreiros competentes, humanos covardes, rainhas de bateria de escola de samba, populações em situação de rua. Estes tipos humanos são presenças da atualidade. Entretanto, questiona-se: qual de nós, leitores, olhamos verticalmente para essas pessoas que transitam por nós nas nossas vidas ordinárias? E quando 
nos deparamos com tais personagens será que conseguimos captar um fragmento de suas realidades que não esteja pautada no estereótipo?

Nestes contos, Sacolinha nos mostra um estilhaço da existência destes personagens atuais, que geralmente não são evidenciados, ou pior, são “esquecidos” pelo olhar do preconceito e da discriminação. Assim, oportuniza aos leitores uma experiência literária que os faz voltar a realidade com um olhar mais aguçado e, provavelmente, mais sensível. No Livro Brechó, Meia-noite e Fantasia, ao promover o encontro irrestrito dos leitores com personagens que passeiam no cotidiano do tempo presente, Sacolinha tanto humaniza também seus personagens quanto faculta a mesma aprendizagem aos seus leitores.

\title{
CHARACTER CONSTRUCTION IN SACOLINHA'S LITERARY WORKS
}

\begin{abstract}
In the end of 90's of century XX, a literature, assigned for some of peripheral, others of delinquent appears in the Brazilian literary scene or even though divergent. This Brazilian writing contemporary has created important spaces in the market publishing, interested in the specialized critical and extended number of readers involved in it. Therefore, we understand as fundamental importance to study it, recognizing the necessity of rise it such as artistic productions to a biggest number of readers for singular potential in its formation, over all, on those age range youth and in peripheral contexts. Thus, this communication presents an analysis around the process elaboration of personages in the production of one of the main exponents of this scene: the Sacolinha Writer. In its tales books, we can observe current personages, men and women who circulate in the poor localities Brazilian. However, for this author the emphasis is on the subjective aspects and in detriment of physical and material characterizations, evidencing the search in humanize them and in it deals with the complexity of these. The used methodology is the bibliographical research with qualitative and interpretative boarding. For this purpose, it is authenticated in Resende (2008), Schollhammer (2011), Dalcastagné (2012) with respect to Brazilian literature contemporary. It is supported in Nascimento (2009), Hollanda (2013, 2015), Reys (2013) to argue peripheral literature. E in Beth Braith (1985) and Rosenfeld (1968) and Cuti (2010), to weave the analysis of the personages. In this movement, we perceives that Sacolinha opts when constructing the personages protagonists of his tales for minimize the physical description and value the psychological profile in intention to take the reader see such so next personages and that they circulate in daily of the societies the contemporaries, for a prism many times ignored for the collectives and over all for the public power.
\end{abstract}

KEYWORDS: Contemporary Brazilian literature; Periphery; Escritor Sacolinha; Character.

\section{REFERÊNCIAS}

BRAIT, Beth. A personagem. São Paulo: Ática, 1985. 
CARRASCOZA, João Anzanello. Vidas nada simples. Prefácio. In: SACOLINHA (2016). Brechó, Meia-Noite e Fantasia. São Paulo: Patuá, 2016.

CANDIDO, Antonio. O direito à Literatura. In: CANDIDO, Antonio. Vários escritos. Rio de Janeiro: Ouro sobre azul / São Paulo: Duas Cidades, 2004.

DALCASTAGNÉ, Regina. Literatura brasileira contemporânea: um território contestado.

Vinhedo, Editora Horizonte / Rio de Janeiro: Editora da uerj, 2012.

EBEL, Laetícia Jensen. Sacolinha - Brechó, Meia-Noite e Fantasia. Estudos da Literatura Brasileira Contemporânea. N No 50, Brasília, Jan./Apr. 2017. Disponível em: http://dx.doi.org /10.1590/2316-40185030, acesso em abril de 2018.

GONZALEZ, Lélia. Por um feminismo afro-latino americano. Disponível em: https://edisciplinas.usp. br/pluginfile.php/271077/mod_resource/content $/ 1 /$ Por $\% 20 u m \% 20$ feminismo\%20Afro-latino-americano.pdf, acesso em: maio de 2018.

HOLLANDA, Heloisa Buarque de. Apresentação. In: REYES, Alejandro. Vozes dos porões: a literatura periférica/ marginal do Brasil. Rio de Janeiro: Aeroplano, 2013.

LAJOLO, Marisa. Literatura: Leitores \& leitura. São Paulo: Moderna, 2001.

PENA, João Camilo. Apresentação. In: TENINA, Lucía et al. Polifonias marginais. Rio de Janeiro: Aeroplano, 2016.

RESENDE, Beatriz. Contemporâneos: expressões da literatura brasileira no século XXI. Rio de Janeiro: Casa da Palavra: Biblioteca Nacional, 2008.

REYES, Alejandro. Vozes dos porões: a literatura periférica/ marginal do Brasil. Rio de Janeiro: Aeroplano, 2013.

SACOLINHA (2006). 85 letras e um disparo. São Paulo: Global, 2007. (Coleção Literatura Periférica).

SACOLINHA (2012). Como a água do rio. Rio de Janeiro: Aeroplano. (Coleção Tramas Urbanas).

SACOLINHA (2016). Brechó, Meia-Noite e Fantasia. São Paulo: Patuá, 2016.

SCHOLLHAMMER, Karl Erich. Ficção brasileira contemporânea. Rio de Janeiro: Civilização Brasileira, 2011.

SILVA, Luiz. (CUTI). Literatura negro-brasileira. São Paulo: Selo Negro, 2010.

Recebido em: 16/07/2018.

Aprovado em: 14/12/2018. 